\title{
Carratelli Unit
}

National Cancer Institute

\section{Source}

National Cancer Institute. Carratelli Unit. NCI Thesaurus. Code C120851.

An arbitrary unit of substance concentration expressed in milligrams per a volume of hydrogen peroxide. One Carratelli unit is equal to $0.8 \mathrm{mg}$ substance per liter of hydrogen peroxide. 